\title{
Determinants of Success and Early Complications in Common Femoral Artery Endarterectomy: A Retrospective Study
}

\author{
Marcel Libertus Johannes Quax *, Daniël Eefting (D) and Herman Joseph Smeets \\ Department of Surgery, Haaglanden Medical Centre, 2501 CK Den Haag, The Netherlands; \\ d.eefting@haaglandenmc.nl (D.E.); h.smeets@haaglandenmc.nl (H.J.S.) \\ * Correspondence: m.1.j.quax@lumc.nl
}

Citation: Quax, M.L.J.; Eefting, D.; Smeets, H.J. Determinants of Success and Early Complications in Common Femoral Artery Endarterectomy: A Retrospective Study. Surgeries 2021, 2, 180-189. https://doi.org/10.3390/ surgeries2020019

Academic Editor: Cornelis F. M. Sier

Received: 6 April 2021

Accepted: 25 May 2021

Published: 29 May 2021

Publisher's Note: MDPI stays neutral with regard to jurisdictional claims in published maps and institutional affiliations.

Copyright: (c) 2021 by the authors. Licensee MDPI, Basel, Switzerland. This article is an open access article distributed under the terms and conditions of the Creative Commons Attribution (CC BY) license (https:// creativecommons.org/licenses/by/ $4.0 /)$.

\begin{abstract}
Introduction: Common femoral artery endarterectomy (CFE) is considered a relatively simple, successful and safe procedure in the literature, but major complications can occur. This retrospective study was performed in order to define characteristics contributing to success or failure after common femoral artery endarterectomy, either performed as a single or hybrid procedure. Methods: A total of 298 patients who underwent CFE in our hospital between 1 January 2011 and 1 January 2017 were included. After exclusion, 227 patients were analyzed. Patient characteristics and outcomes were derived from the patient records. Follow-up was 30 days postoperatively. Outcomes were analyzed by the chi-square test and regression analysis. Clinical success was defined as a combination of technical success, improvement in the ankle-brachial index, increased walking distance and "no complications." Results: The procedure was clinically successful in $74.4 \%$ of the patients, and in $25.6 \%$, a complication occurred. The Rutherford class improved in $65.1 \%$ of the patients with 1.6 (SD 1.3) class points. The ankle-brachial index improved in $44.8 \%$ of the cases, with an average of $116.6 \%$. The most contributing factors for complications such as death, unplanned amputation, surgical site infection, thrombosis and longer hospital admission were emergency operation and a higher ASA classification. Significantly more complications also occurred in patients with renal failure, congestive heart disease, a high Rutherford classification and previous groin incision. A higher Rutherford class was the only factor correlating with an increase in the anklebrachial index. When single CFE (48.9\% of cases) and hybrid procedures (51.1\%) were compared, no significant difference in success or failure was found. Conclusion: Limb ischemia requiring emergency operation and preoperative comorbidity were identified as the most important factors predictive for complications following femoral artery endarterectomy. Combining femoral endarterectomy with an endovascular intervention does not seem to increase the risk of a postoperative complication.
\end{abstract}

Keywords: common femoral artery endarterectomy; hybrid procedure; successful outcome; vascular surgery; emergency operation

\section{Introduction}

Surgical endarterectomy is usually the preferred option for surgery in patients with isolated significant stenotic atherosclerotic lesions in the common femoral artery [1]. In the case of multilevel lesions, a common femoral endarterectomy procedure (CFE) can be combined with a transluminal angioplasty, a so-called "hybrid procedure" [2]. Although usually considered a relatively simple, successful and safe procedure [3], serious complications following CFE may occur, even leading to major amputation or death. Derksen et al. showed a complication rate within 30 days postoperative of 30.7\% [4], Nguyen 23.5\% [5] and Zou 24.4\% [6]. Unfortunately, the factors that lead to these complications are not fully elucidated yet. Some studies have indicated variables that may correlate with these major complications. However, it remains uncertain which variables, and to what extent, contribute to the occurrence of these complications. Recent studies show no increase in the complication rate when endovascular revascularization is added to CFE in a hybrid 
procedure [7]. Most of the literature was focused on factors contributing to complications after CFE, but factors contributing to success were barely analyzed. There is a difference between technically successful and clinically successful outcomes. Technical success is defined as a procedure removal or dilation of significantly obstructing stenosis. When the course is without complications, it is defined as clinically successful. Even procedures that are technically successful can be accompanied by complications that affect the successful clinical outcome, for example, due to infection. Clinical improvement can be seen as a better situation than the situation preoperatively. This retrospective study was performed in order to define characteristics contributing to success or failure after common femoral artery endarterectomy.

\section{Materials and Methods}

\subsection{Design}

A retrospective study was performed, including all patients who underwent endarterectomy of the common femoral artery between 1 January 2011 and 1 January 2017 in the Haaglanden Medical Center, The Hague, The Netherlands. The institutional board committee approved this study.

\subsection{Patient Selection}

All patients who underwent any procedure including CFE were included. Operation indication was either patients with chronic limb ischemia or acute (on chronic) ischemia. Excluded were those in whom additional surgical procedures were performed, such as the insertion of an aorta bifemoral prosthesis or femoral-distal bypass, removal of a foreign body (closure device, stent) and those in whom a false aneurysm of the femoral artery was repaired. Patients additionally undergoing endarterectomy of the superficial or profundal femoral artery, with or without profundal plasty, and patients undergoing any proximal or distal additional endovascular treatment were not excluded. Exclusions are further explained in Section 3.

Patient characteristics were derived from the patient records. For comorbidity analysis, the American Society of Anesthesiologists classification (ASA) was used. Highlighted comorbidities were congestive heart failure, COPD, sepsis (criteria for SIRS [8]), renal failure (eGFR $<60 \mathrm{~mL} / \mathrm{min} / 1.73 \mathrm{~m}^{2}$ ), hemodialysis and diabetes mellitus.

Severity of PAD was scored with the Rutherford classification [9], ankle-brachial index (pre- and postoperative) and TASC classification based on computed tomographic angiography [10].

If the treatment was conducted within $24 \mathrm{~h}$ after the presentation of acute ischemia, the intervention was registered as an emergency operation. Furthermore, previous ipsilateral groin incision or PTA (percutaneous transluminal angioplasty) and procedure duration were registered.

\subsection{Outcome Parameters}

Primary outcome measures were postoperative complications and success of the procedure. The complications were categorized into surgical site infections (SSI), bleeding, reoperation for any reason, unplanned amputation, death and arterial or venous thrombosis. Other complications were categorized as "miscellaneous". Success of the treatment was defined as improvement in walking distance (which is subjective as it was a question in follow-up), increase in the Rutherford classification and increase in the anklebrachial index. Clinical success was defined as technical success, success of treatment and "no complications." Technical success is defined as a procedure removal or dilation of significantly obstructing stenosis. Clinical improvement is seen as improvement in the Rutherford classification.

Secondary outcome measures were the length of admission and healing of peripheral wounds.

Perioperative complications were registered until 30 days postoperative. 


\subsection{Definitions}

Surgical site infections were classified by the Szilagyi classification [11]. Bleeding was included as a complication when reoperation was needed. "Miscellaneous" included cardiac (myocardial infarction, hypotension, atrial fibrillation, congestive heart failure), pulmonary (pneumonia, exacerbated COPD) and renal complications (acute renal insufficiency [12]), as well as stroke, delirium or anemia.

Amputation was defined as a complication if it was unplanned preoperatively. In the analysis, the amputations were divided into toe, lower leg and upper leg amputations.

\subsection{Follow-Up}

For this study, follow-up was 30 days postoperatively. Only peripheral wound healing was followed until 6 months postoperatively. Follow-up was conducted by a vascular surgeon, a vascular surgery resident or a specialized wound care nurse.

\subsection{Data Analysis}

Data were registered in Castor electronic data capture (Castor, Amsterdam, The Netherlands). Data analysis was performed by IBM SPSS Statistics for Windows, version 22.0 (IBM Corp. Armonk, NY, USA). The Pearson chi-square test was used to compare the categorical variables. Logistic and linear regressions were used to evaluate risk factors. All $p$-values below 0.05 were interpreted as statistical significance.

\section{Results}

Of a total of 298 included patients, patients undergoing aorta reconstruction $(n=19)$ or bypass surgery $(n=43)$ were excluded, as well as those patients in whom a foreign body (closure device, stent) was removed $(n=4)$, those who underwent repair of a pseudoaneurysm $(n=3)$ and those who underwent other surgery in combination with CFE $(n=2)$. Baseline characteristics of the remaining 227 are shown in Table 1. Single CFE was performed in $48.9 \%$ of the cases, and a hybrid procedure was performed in $51.1 \%$. Of the operated patients, $47.6 \%$ suffered intermittent claudication.

Complications and success of the procedures are shown in Table 2. Technical success was achieved in all procedures; $74.4 \%$ of the procedures did not have a complication. In $65.1 \%$, the Rutherford classification improved, and in $44.8 \%$, the ankle-brachial index improved after the procedure. The walking distance improved in $68 \%$ and peripheral wounds healed within 6 months in $44.8 \%$ of the cases.

Grade 1 SSIs were treated with antibiotics, and five out of six patients with a grade 2 infection were reoperated, where one was successfully treated with antibiotics. In the patients with grade 3 infections, four reoperations were performed, while one patient died due to infection 14 days postoperatively.

From the five patients with an arterial thrombosis, four needed reoperation and one patient died due to the thrombosis. In the 30 days postoperatively, $2.2 \%$ of the patients had one or multiple toes amputated unplanned; in 1.3\%, an unplanned below knee amputation was necessary; and in $2.6 \%$, an unplanned above knee amputation was necessary.

Post-procedure, on average, the ankle brachial index was increased $115.4 \%$ (from 0.48 to $0.55, p<0.001$ ), and the Rutherford classification increased, on average, with 1.6 class points (from 5.2 to $3.6, p<0.001$, standard deviation 1.3).

Tables 3 and 4 show the regression numbers of the determinants which had a significant correlation with the outcome. Due to the large amount of data collected, only the significant correlations are pointed out (see Appendix A for complete regression outcome). When a factor had a significant correlation with the outcome, the odds ratio is mentioned in this table. Emergency procedure was significantly correlated with complications (OR 3.0), unplanned amputations (OR 3.3), arterial thrombosis (OR 3.8), admission duration (RC 7.05) and death (OR 11.3). High ASA classification had a significantly higher odds ratio on complications (2.4), SSI (2.4), unplanned amputation (2.7) and death (6.9). Previous groin incision was correlated with a significantly higher risk of complications 
(OR 2.2), SSI (OR 3.2) and arterial thrombosis (OR 4.3). Renal failure was correlated with complications (OR 2.0), SSI (OR 1.7) and longer peripheral wound healing (RC 9.3).

Higher Rutherford classification had a significant correlation with the increase in the ankle-brachial index (RC 77.9). There were no other factors correlating significantly with successful outcome.

When the correlation between ASA classification and complications was corrected for emergency procedure, no difference in significance was found (OR 2.75, CI 2.44-3.07).

Next, we added the hybrid procedure as a determinant to the regression analysis. In $76.7 \%$, an endovascular procedure was performed in the iliac arteries; in $18.1 \%$, in the femoral arteries; and in $5.2 \%$, in both iliac and femoral arteries. This did not show a significant correlation with complications (CI 0.604-1.771). Finally, outcome after hybrid procedure and that after common femoral artery endarterectomy were compared as separate groups well by the chi-square test, see Table 5 . The only, marginal, significant difference was in bleeding needing a reoperation. In $4.3 \%$, re-occlusion occurred in the hybrid group, which was not significantly different from single CFE (6.2\%).

Table 1. Baseline characteristics of study group.

\begin{tabular}{|c|c|c|}
\hline \multicolumn{3}{|c|}{ Total Group $n=227\left(\mathrm{SD}^{1}\right)$} \\
\hline Age, in years & & 70.2 \\
\hline Sex (\% male) & & 59.4 \\
\hline $\mathrm{ASA} \geq 3(\%)$ & & 62.4 \\
\hline \multirow[t]{7}{*}{ Rutherford $\geq 4(\%)$} & & 52.3 \\
\hline & Rutherford 1 & 2.2 \\
\hline & Rutherford 2 & 12.7 \\
\hline & Rutherford 3 & 32.8 \\
\hline & Rutherford 4 & 21.8 \\
\hline & Rutherford 5 & 27.1 \\
\hline & Rutherford 6 & 3.1 \\
\hline \multirow[t]{4}{*}{ TASC classification (\%) } & $\mathrm{A}$ & 13.5 \\
\hline & $\mathrm{B}$ & 32.8 \\
\hline & $\mathrm{C}$ & 34.1 \\
\hline & $\mathrm{D}$ & 19.7 \\
\hline Acute ischemia (\%) & & 14.8 \\
\hline Diabetes mellitus (\%) & & 38.0 \\
\hline Renal dysfunction (\%) & & 27.5 \\
\hline Congestive heart failure (\%) & & 10.5 \\
\hline COPD $(\%)$ & & 20.5 \\
\hline Sepsis $(\%)$ & & 1.3 \\
\hline Smoking (\%) & & 30.1 \\
\hline Body mass index & & $35.9(4.95)$ \\
\hline Emergency operation (\%) & & 17.0 \\
\hline $\begin{array}{l}\text { Operation duration (in } \\
\text { minutes) }\end{array}$ & & $163.1(61.97)$ \\
\hline Hybrid procedure (\%) & & 51.1 \\
\hline \multirow[t]{4}{*}{ Patch used $(\%)$} & & 95.2 \\
\hline & Venous patch & 71.2 \\
\hline & Synthetic patch & 18.8 \\
\hline & Bovine patch & 3.2 \\
\hline
\end{tabular}

\footnotetext{
${ }^{1} \mathrm{SD}=$ standard deviation.
} 
Table 2. Outcome of treatment in cohort $(n=227)$. SD $=$ standard deviation. First shown is the percentage of operations without any complication. As one patient could suffer from more than one complication, the total number of complications is mentioned as well. Under "Result of complication", no actual complication is registered but rather the number of operations or mortalities due to the complications mentioned above.

\begin{tabular}{|c|c|c|}
\hline \multicolumn{3}{|c|}{ Total Cohort $(n=227)$} \\
\hline & $n=(\mathrm{SD})$ & $\%$ \\
\hline Operations without complication & 169 & 74.4 \\
\hline Operations with 1 or more complications & 58 & 25.6 \\
\hline Complications total & 69 & 30.2 \\
\hline SSI & 26 & 11.4 \\
\hline Grade 1 & 15 & 6.6 \\
\hline Grade 2 & 6 & 2.6 \\
\hline Grade 3 & 5 & 2.2 \\
\hline Arterial thrombosis & 5 & 2.2 \\
\hline Miscellaneous & 28 & 12.2 \\
\hline Improvement in ankle-brachial index & 114 & 44.8 \\
\hline $\begin{array}{l}\text { Percentual improvement in ankle-brachial } \\
\text { index }\end{array}$ & 0.48 to 0.55 & $116.6(483)$ \\
\hline Improvement in Rutherford class & 149 & 65.1 \\
\hline Rutherford improvement in class & 3.6 to 5.2 & $1.6(1.3)$ \\
\hline $\begin{array}{l}\text { Improved walking distance (subjective } \\
\text { improved) }\end{array}$ & 151 & 66.8 \\
\hline Healing peripheral wound within 6 months & 26 & 44.1 \\
\hline \multicolumn{3}{|c|}{ Result of Complication } \\
\hline Reoperation & 36 & 15.7 \\
\hline Unplanned amputation & 15 & 6.6 \\
\hline Death & 9 & 3.9 \\
\hline
\end{tabular}

Table 3. Multivariate regression analysis of risk factors vs. outcome.

\begin{tabular}{cccccc}
\hline Complication & Odds & $\mathbf{9 5 \%}$ CI & Death & Odds & $\mathbf{9 5 \% ~ C I ~}$ \\
\hline Emergency procedure & 3.0 & $1.50-6.17$ & Emergency procedure & 11.3 & $2.7-47.57$ \\
ASA & 2.5 & $2.46-2.63$ & ASA & 6.9 & $1.55-30.7$ \\
Previous groin incision & 2.2 & $1.07-4.52$ & Renal failure & 5.7 & $1.38-23.4$ \\
Renal failure & 2.0 & $1.13-3.70$ & Acute ischemia & 5.0 & $1.28-19.8$ \\
Rutherford & 1.7 & $1.30-2.18$ & Heart failure & 4.7 & $1.1-20.24$ \\
\hline SSI & Odds & $\mathbf{9 5 \%}$ CI & Thrombosis & Odds & $\mathbf{9 5 \% ~ C I ~}$ \\
\hline Previous groin incision & 3.2 & $1.32-7.95$ & Acute ischemia & 4.6 & $1.37-15.5$ \\
ASA & 2.4 & $1.06-5.24$ & Previous groin incision & 4.3 & $1.28-14.3$ \\
Renal failure & 2.4 & $1.03-5.36$ & Emergency procedure & 3.8 & $1.15-12.8$ \\
\hline Unplanned Amputation & Odds & $\mathbf{9 5 \%} \mathbf{C I}$ & & & \\
\hline Emergency procedure & 3.3 & $1.32-8.06$ & & & \\
ASA & 2.7 & $1.14-6.17$ & & & \\
Rutherford & 2.7 & $1.66-4.30$ & & & \\
TASC & 1.9 & $1.17-3.08$ & & & \\
\hline
\end{tabular}


Table 4. Multivariate regression analysis of risk factor vs. successful outcome.

\begin{tabular}{|c|c|c|c|c|c|}
\hline Duration Admission & RC & $95 \%$ CI & $\begin{array}{c}\text { Increased Walk } \\
\text { Distance }\end{array}$ & Odds & $95 \% \mathrm{CI}$ \\
\hline Sepsis & 54.01 & $47.4-60.7$ & Rutherford & 0.60 & $0.45-0.80$ \\
\hline Emergency operation & 7.05 & $4.7-9.4$ & Previous PTA & 0.51 & $0.27-0.95$ \\
\hline Acute ischemia & 3.88 & $1.2-6.5$ & Diabetes mellitus & 0.46 & $0.25-0.84$ \\
\hline ASA & 2.46 & $0.8-4.1$ & Renal failure & 0.46 & $0.24-0.87$ \\
\hline Rutherford & 1.83 & $1.1-2.6$ & ASA & 0.41 & $0.22-0.76$ \\
\hline $\begin{array}{l}\text { Duration Wound } \\
\text { Healing }\end{array}$ & RC & $95 \% \mathrm{CI}$ & $\begin{array}{c}\text { Increased } \\
\text { Ankle-Brachial Index }\end{array}$ & RC & $95 \% \mathrm{CI}$ \\
\hline Sepsis & 55.9 & $21.6-90.2$ & Rutherford & 77.80 & $8.9-146.7$ \\
\hline Renal failure & 9.33 & $0.8-17.9$ & & & \\
\hline
\end{tabular}

Table 5. Analysis of the outcomes after CFE versus hybrid procedure.

\begin{tabular}{cccc}
\hline Outcome & CFE & Hybrid & $p$-Value \\
\hline Complications total (\%) & 33.7 & 26.7 & 0.304 \\
SSI (\%) & 10.6 & 12.1 & 0.730 \\
Bleeding with reoperation (\%) & 7.1 & 1.7 & 0.047 \\
Thrombosis (\%) & 1.0 & 3.4 & 0.522 \\
Miscellaneous (\%) & 15.0 & 9.5 & 0.199 \\
Bleeding without operation (\%) & 6.5 & 4.3 & 0.199 \\
Ankle-brachial index improvement (\%) & 103.6 & 127.2 & 0.775 \\
Rutherford improvement (in class) & 1.56 & 1.63 & 0.690 \\
Improved walking distance (\%) & 63.7 & 69.8 & 0.507 \\
Reoperation (\%) & 15.9 & 15.5 & 0.932 \\
Unplanned amputation (\%) & 6.2 & 6.9 & 0.830 \\
Death (\%) & 4.4 & 3.4 & 0.704 \\
\hline
\end{tabular}

\section{Discussion}

In the current study, we demonstrated that factors that predict a poor clinical outcome of CFE procedures are emergency operation, a high Rutherford class, a high ASA classification, renal failure and previous groin incision. A high Rutherford class and emergency operations suggest the presence of chronic or acute limb-threatening ischemia as a major contributor to poor outcome, together with preoperative comorbidity, as illustrated by high ASA and renal failure. On the positive side, a high preoperative Rutherford class was the only determinant that significantly correlated with an increase in the ankle-brachial index.

The significant complication rate in our overall cohort $(25.6 \%)$ is in the upper range when compared with the numbers reported in the literature, namely, $14-25 \%[5,6]$. Nguyen et al. [5] reported a 30-day complication rate of 23.5\% and Zhou et al. 24.4\% [6]. In our population, more patients suffered from ischemic rest pain $(52 \%$ vs. $23 \%$ in Nguyen's and $16 \%$ in Zhou's article). Our population also suffered more comorbidities, with $62 \%$ of the patients having an ASA classification $>3(62.4 \%$ vs. $20.5 \%$ in Nguyen's paper), $10.5 \%$ suffering from congestive heart disease (vs. 3.0\%), 20.5\% with COPD (vs $13.7 \%$ ) and $38 \%$ with diabetes mellitus (vs. 33\%). Emergency operation was performed more frequently in our population (17\% vs. $12.8 \%$ in Nguyen's and $7.5 \%$ in Zhou's paper). Likely, the worse condition of our patients and the higher number of emergency procedures explain the higher number of complications. Within 30 days postoperatively, mortality in Nguyen's paper was 3.4\%, comparable to $3.9 \%$ in our population, while $1.5 \%$ suffered from cardiovascular complications, acute renal dysfunction $(0.9 \%)$, pulmonary complications $(3.3 \%)$ and, in $8.4 \%$, wound-related complications. Our study shows comparable wound-related complications $(11.4 \%)$, although we did not score wound dehiscence unless there was an infection. Derksen et al. described $14 \%$ wound infections [4]; Kechagias described 17\% wound infections, 9\% hematoma and $5 \%$ seroma [13]. Compared to the literature, the population we studied in general 
had a more progressed state of peripheral artery disease and had a higher number of emergency operations.

Following emergency operations, our analysis showed more reoperations, amputations, longer hospital admission times and higher mortality rates. Patients undergoing these emergency operations were not observed to have a higher ASA classification. Nguyen et al. showed in their prediction model that the risk on mortality is three times bigger in an emergency procedure [14]. Additionally, Bonvini et al. showed a correlation between emergency procedure and reoperation [15]. It therefore seems that an emergency situation, caused by critical limb-threatening ischemia, is an important risk factor itself.

The observed complication rates implicate that femoral artery endarterectomy, with or without endovascular treatment, should be considered a procedure with a high risk of complications, for which preoperative (multi-)comorbidities and stage of ischemia are the most important risk factors. This calls for a strong preoperative optimization of the patient's condition. In emergency cases, little time for optimization is available, which makes the combination of multimorbidity and emergency surgery ominous and hard to improve.

Regression analysis showed a significantly higher risk on complications and amputations in patients with a higher Rutherford classification as well. When comparing the percentage of complications with those reported in the literature, our results seem worse. However, when the higher comorbidity rate, the higher Rutherford classification and the higher percentage of emergency operations in our population are taken into consideration, our outcomes seem to be better.

Derksen et al. analyzed risk factors for surgical site infections and found a significant correlation between previous groin incision $(p=0.013)$ and surgical site infection [4]. Our study confirmed this correlation (OR 3.2). A correlation between postoperative wound drain and surgical site infections was suggested by Derksen et al. as well. Therefore, the use of wound drains was avoided as a standard in our population. It was to be expected that a higher BMI and a longer operation time would have given a higher risk on infections, but regression analysis showed no significant correlation between BMI and operation duration and surgical site infections (see Appendix A). Nutritional status was not investigated but should be considered as a risk factor as well.

When hybrid procedures and CFE alone were compared, no significant differences in outcome were found, despite a longer duration of the procedure and despite more extended atherosclerotic disease in the "hybrid" patients. A proper explanation for this surprising finding is lacking, but Kang et al. conducted a short analysis as well and described no statistically significant differences in complications [16].

Limitations of this retrospective study are missing data due to incomplete patient files, and selection and observer bias due to the retrospective scoring of comorbidities and postoperative outcomes. By using standardized measure tools and definitions, this bias was reduced to the minimum.

\section{Conclusions}

In conclusion, we can state that (acute) limb-threatening ischemia and preoperative comorbidity were identified as the most important factors predictive for complications following femoral artery endarterectomy. Preoperative optimization seems mandatory but may be difficult to execute if the time to surgery is short given the seriousness of the ischemia.

Author Contributions: Conceptualization, M.L.J.Q., H.J.S.; Formal analysis, M.L.J.Q.; Investigation, M.L.J.Q.; Methodology, M.L.J.Q., H.J.S.; Writing—original draft, M.L.J.Q.; Writing—review \& editing, H.J.S. and D.E. All authors have read and agreed to the published version of the manuscript.

Funding: This research received no external funding.

Institutional Review Board Statement: The study was conducted according to the guidelines of the Declaration of Helsinki, and approved by the Institutional Review Board (METC South-West Holland). 
Informed Consent Statement: Not applicable.

Data Availability Statement: The data presented in this study are available on request from the corresponding author.

Conflicts of Interest: The authors declare no conflict of interest.

Appendix A

Table A1. Complete Outcome.

\begin{tabular}{|c|c|c|c|c|c|c|c|c|}
\hline \multirow[t]{2}{*}{ Characteristics } & \multicolumn{2}{|c|}{ Hospital Stay } & \multicolumn{2}{|c|}{ Wound Healing } & \multicolumn{2}{|c|}{$\begin{array}{c}\text { Ankle-Brachial } \\
\text { Improvement }\end{array}$} & \multicolumn{2}{|c|}{$\begin{array}{c}\text { Improvement Walking } \\
\text { Distance }\end{array}$} \\
\hline & Reg Coef & $p$-Value & Reg Coef & $p$ & Reg Coef & $p$ & Odds & CI \\
\hline \multicolumn{9}{|l|}{ Procdure } \\
\hline Hybrid & -0.927 & 0.324 & 3.768 & 0.334 & 23,557 & 0.775 & 0.071 & 0.254 \\
\hline \multicolumn{9}{|l|}{ Patient Characteristics } \\
\hline Age & 0.005 & 0.895 & -0.154 & 0.399 & 5.492 & 0.161 & 0.991 & $0.965-1.018$ \\
\hline Gender & 1.288 & 0.176 & -1.03 & 0.797 & 155,479 & 0.063 & 1.05 & $0.573-1.927$ \\
\hline ASA classification & 2.469 & 0.004 & 0.915 & 0.793 & 83,017 & 0.306 & 0.411 & $0.222-0.763$ \\
\hline Rutherfurd classification & 1.828 & $<0.001$ & 2.224 & 0.191 & 77,804 & 0.027 & 0.599 & $0.451-0.796$ \\
\hline Ankle-brachial index & -2.432 & 0.053 & 1.505 & 0.872 & $-704,202$ & $<0.001$ & 1.578 & $0.384-6.478$ \\
\hline TASC & -0.335 & 0.497 & 0.279 & 0.895 & 76,171 & 0.074 & 0.86 & $0.626-1.181$ \\
\hline Acute ischemia & 3.88 & 0.004 & 6.436 & 0.263 & $-73,676$ & 0.677 & 1.054 & $0.44-2.527$ \\
\hline \multicolumn{9}{|l|}{ Comorbidities } \\
\hline Congestive heart failure & 0.833 & 0.597 & 9.601 & 0.171 & $-87,432$ & 0.523 & 0.721 & $0.273-1.905$ \\
\hline COPD & -1.263 & 0.277 & -6.442 & 0.173 & 105,021 & 0.305 & 1.118 & $0.52-2.403$ \\
\hline Sepsis & 54,014 & $<0.001$ & 55,894 & 0.002 & & & 0.195 & $0.017-2.195$ \\
\hline Renal disfunction & 0.65 & 0.54 & 9.327 & 0.033 & 51,431 & 0.571 & 0.461 & $0.244-0.872$ \\
\hline Dialysis & -0.231 & 0.948 & -9.785 & 0.505 & $-98,044$ & 0.777 & 0.393 & $0.054-2.857$ \\
\hline Diabetes mellitus & -0.586 & 0.549 & 7.281 & 0.069 & 3.248 & 0.969 & 0.458 & $0.25-0.838$ \\
\hline \multicolumn{9}{|l|}{ Operations Characteristics } \\
\hline Emergency procedure & 7.045 & $<0.001$ & -6.276 & 0.285 & 16,992 & 0.919 & 1.463 & $0.655-3.270$ \\
\hline Previous groin incision & 0.337 & 0.796 & 3.016 & 0.581 & $-65,306$ & 0.623 & 0.811 & $0.358-1.841$ \\
\hline Previous PTA & -0.332 & 0.745 & -1.852 & 0.66 & 25,675 & 0.769 & 0.509 & $0.274-0.946$ \\
\hline Antibiotics & 1.553 & 0.101 & -3.634 & 0.358 & -138.89 & 0.092 & 0.968 & $0.534-1.756$ \\
\hline Antibiotics durations (days) & -0.009 & 0.872 & 0.199 & 0.449 & -1.959 & 0.415 & 1.019 & $0.954-1.089$ \\
\hline Contralateral groin opened & 0.602 & 0.661 & 0.386 & 0.946 & $-60,337$ & 0.623 & 1.365 & $0.553-3.369$ \\
\hline Operation duration & 0.006 & 0.44 & 0.005 & 0.871 & 0.254 & 0.696 & 1.001 & $0.996-1.006$ \\
\hline \multirow[t]{2}{*}{ Bloodloss } & 0.003 & 0.005 & -0.009 & 0.155 & 0.024 & 0.873 & 0.999 & $0.999-1.000$ \\
\hline & \multicolumn{3}{|c|}{ Complication } & \multicolumn{3}{|c|}{ Surgical site infection } & \multicolumn{2}{|c|}{ Thrombosis } \\
\hline Procdure & odds & & & odds & $95 \%$ & & odds & $95 \% \mathrm{CI}$ \\
\hline Hybrid & 1.034 & 0.6 & .771 & 0.947 & 0.424 & 16 & 1.466 & $0.451-4.762$ \\
\hline \multicolumn{9}{|l|}{ Patient characteristics } \\
\hline Age & 1.01 & 0.9 & .034 & 1.004 & 0.696 & 40 & 0.966 & $0.92-1.015$ \\
\hline Gender & 1.46 & 0.8 & .519 & 0.503 & 0.224 & 31 & 0.469 & $0.144-1.525$ \\
\hline ASA classification & 2.395 & 1.4 & .066 & 2.354 & 1.057 & 43 & 0.485 & $0.176-1.339$ \\
\hline Rutherfurd classification & 1.683 & 1.3 & .175 & 1.04 & 0.730 & 83 & 1.388 & $0.82-2.35$ \\
\hline Ankle-brachial index & 0.282 & 0.0 & .131 & 0.98 & 0.125 & 05 & 1.615 & $0.05-52,145$ \\
\hline TASC & 1.253 & 0.9 & .669 & 1.09 & 0.713 & 65 & 1.832 & $0.937-3.579$ \\
\hline Acute ischemia & 1.939 & & 044 & 1.042 & 0.335 & 39 & 4.606 & $1.370-15,484$ \\
\hline Comorbidities & & & & & & & & \\
\hline Congestive heart failure & 2.214 & 0.9 & .195 & 1.574 & 0.494 & 10 & 0.763 & $0.094-6.182$ \\
\hline COPD & 1.082 & 0.5 & .095 & 1.749 & 0.713 & 89 & 0.336 & $0.042-2.67$ \\
\hline Sepsis & big & & & 3.827 & 0.335 & 688 & 0 & NS \\
\hline Renal disfunction & 2.047 & 1.1 & .701 & 2.353 & 1.033 & 58 & 0.226 & $0.029-1.786$ \\
\hline Dialysis & 0.566 & 0.0 & .533 & 0 & $\mathrm{~N}$ & & 0.220 & $\begin{array}{l}\text { NS } \\
\text { NS }\end{array}$ \\
\hline Diabetes mellitus & 1.48 & 0.8 & .567 & 0.947 & 0.413 & 75 & 0.308 & $0.066-1.441$ \\
\hline Risk Factor Atherosclerosis & & & & & & & & \\
\hline Hypercholesterolemia & 0.573 & 0.2 & .477 & 0.471 & 0.144 & 48 & 0.762 & $0.09-6.439$ \\
\hline High LDL & 0.584 & 0.2 & .582 & 0.61 & 0.163 & 84 & 0.67 & $0.079-5.699$ \\
\hline Smoking & 1.368 & 0.7 & 623 & 1.167 & 0.461 & 55 & 4.052 & $0.761-21.57$ \\
\hline $\begin{array}{l}\text { smoking } \\
\text { vs. quit }\end{array}$ & 0.854 & 0.4 & .646 & 0.667 & 0.237 & 373 & 3.672 & $0.691-19,512$ \\
\hline BMI & 1.037 & 0.9 & .096 & 1.013 & 0.936 & 97 & 1.048 & $0.942-1.165$ \\
\hline Operation Characteristics & & & & & & & & \\
\hline Emergency procedure & 3.04 & 1.4 & .165 & 1.463 & 0.549 & 02 & 3.845 & $1.153-12,823$ \\
\hline Previous groin incision & 2.201 & 1.0 & .518 & 3.241 & 1.322 & 46 & 4.286 & $1.279-14,357$ \\
\hline Previous PTA & 1.615 & 0.9 & .861 & 0.908 & 0.377 & 84 & 1.096 & $0.319-3.763$ \\
\hline Antibiotics & 0.779 & 0.4 & .337 & 0.511 & 0.223 & 71 & 2.972 & $0.783-11.28$ \\
\hline Contralateral groin opened & 1.292 & 0.5 & .791 & 2.023 & 0.745 & 195 & 1.297 & $0.27-6.218$ \\
\hline Use of patch & 0.312 & & 1.1 & 1.354 & 0.166 & 015 & 0.115 & $0.026-0.507$ \\
\hline Operation duration & 0.999 & 0.9 & .003 & 1.001 & 0.995 & 08 & 1.004 & $0.995-1.013$ \\
\hline Bloodloss & 1.001 & 1.0 & 002 & 1.001 & $1.0-$ & & 1.001 & $1.0-1.002$ \\
\hline
\end{tabular}


Table A1. Cont.

\begin{tabular}{|c|c|c|c|c|c|c|}
\hline \multirow[t]{2}{*}{ Characteristics } & Hospital Stay & Wound & Wound Healing & $\begin{array}{c}\text { Ankle-Brachial } \\
\text { Improvement }\end{array}$ & \multicolumn{2}{|c|}{$\begin{array}{c}\text { Improvement Walking } \\
\text { Distance }\end{array}$} \\
\hline & Reg Coef & Reg Coef & $p$ & Reg Coef $p$ & Odds & CI \\
\hline & \multicolumn{2}{|r|}{ Reoperation } & \multicolumn{2}{|c|}{ Unplanned amputation } & \multicolumn{2}{|l|}{ Death } \\
\hline Procedure & odds & $95 \% \mathrm{CI}$ & odds & $95 \%$ CI & odds & $95 \% \mathrm{CI}$ \\
\hline Hybrid & 0.862 & $0.441-1.684$ & 0.654 & $0.281-1.523$ & 0.771 & $0.202-2.949$ \\
\hline \multicolumn{7}{|l|}{ Patient Characteristics } \\
\hline Age & 0.998 & $0.969-1.028$ & 1.034 & 0.995-1.075 & 1.028 & $0.968-1.093$ \\
\hline Gender & 1.42 & $0.724-2.783$ & 1.244 & $0.525-2.949$ & 1.875 & $0.49-7.176$ \\
\hline ASA classification & 1.856 & $0.977-3.526$ & 2.651 & $1.139-6.17$ & 6.897 & $1.548-30,727$ \\
\hline Rutherfurd classification & 1.38 & $1.016-1.873$ & 2.668 & $1.656-4.299$ & 1.288 & $0.71-2.335$ \\
\hline Ankle-brachial index & 0.351 & $0.061-2.041$ & 0.048 & $0.005-0.475$ & 0.099 & $0.002-6.466$ \\
\hline TASC & 1.029 & $0.723-1.463$ & 1.902 & $1.174-3.081$ & 1.089 & $0.697-1.701$ \\
\hline Acute ischemia & 1.501 & $0.625-3.606$ & 1.5 & $0.522-4.312$ & 5.04 & $1.281-19,835$ \\
\hline \multicolumn{7}{|l|}{ Comorbidities } \\
\hline Congestive heart failure & 1.188 & $0.417-3.386$ & 1.743 & $0.544-5.585$ & 4.714 & $1.098-20.24$ \\
\hline COPD & 0.887 & $0.380-2.069$ & 1.248 & $0.468-3.324$ & 1.989 & $0.478-8.267$ \\
\hline Sepsis & big & NS & 0 & NS & 0 & NS \\
\hline Renal disfunction & 2.07 & $1.027-4.169$ & 1.887 & $0.799-4.456$ & 5.684 & $1.376-23,478$ \\
\hline Dialysis & 0 & NS & 2.778 & $0.278-27,774$ & 9 & $0.841-96,338$ \\
\hline Diabetes mellitus & 1.818 & $0.925-3.572$ & 1.425 & $0.608-3.340$ & 0.804 & $0.196-3.299$ \\
\hline \multicolumn{7}{|l|}{ Risk Factor Atherosclerosis } \\
\hline \multirow{2}{*}{$\begin{array}{c}\text { Hypercholesterolemia } \\
\text { High LDL }\end{array}$} & 1.901 & $0.42-8.596$ & 0.603 & $0.161-2.249$ & 0.168 & $0.038-0.734$ \\
\hline & 1.656 & $0.363-7.565$ & 0.521 & $0.138-1.971$ & 0.145 & $0.033-0.643$ \\
\hline \multirow[t]{3}{*}{ Smoking } & 1.3 & $0.577-2.93$ & 1.819 & $0.723-4.579$ & 2.672 & $0.615-11,605$ \\
\hline & 1.161 & $0.518-2.603$ & 0.529 & $0.159-1.763$ & 0.456 & $0.046-4.478$ \\
\hline & 1.074 & $1.007-1.146$ & 0.979 & $0.897-1.069$ & 1.019 & $0.895-1.159$ \\
\hline \multicolumn{7}{|l|}{ Operation Characteristics } \\
\hline Emergency procedure & 1.703 & $0.755-3.839$ & 3.262 & $1.321-8.056$ & 11,333 & $2.7-47.57$ \\
\hline Previous groin incision & 1.336 & $0.561-3.185$ & 1.395 & $0.487-3.994$ & 1.563 & $0.311-7.846$ \\
\hline Previous PTA & 2.089 & $1.052-4.147$ & 2.215 & $0.956-5.134$ & 2.854 & $0.743-10,964$ \\
\hline Antibiotics & 0.512 & $0.258-1.017$ & 0.853 & $0.371-1.959$ & 1.928 & $0.47-7.905$ \\
\hline Contralateral groin opened & 0.624 & $0.206-1.889$ & 2.261 & $0.825-6.2$ & 3.429 & $0.811-14,493$ \\
\hline Use of patch & 0.369 & $0.103-1.325$ & 0.299 & $0.074-1.212$ & big & NS \\
\hline Operation duration & 0.994 & $0.987-1.0$ & 1.002 & $0.996-1.009$ & big & NS \\
\hline Bloodloss & 1 & $0.999-1.001$ & 1.001 & $1.0-1.002$ & 1.001 & $1.0-1.002$ \\
\hline
\end{tabular}

Significant values are typed in red.

\section{References}

1. Norgren, L.; Hiatt, W.R.; Dormandy, J.A.; Nehler, M.R.; Harris, K.A.; Fowkes, F.G. Inter-society consensus for the management of peripheral arterial disease (TASC II). Eur. J. Vasc. Endovasc. Surg. 2007, 45, S1-S75. [CrossRef] [PubMed]

2. Dosluoglu, H.H.; Lall, P.; Cherr, G.S.; Harris, L.M.; Dryjski, M.L. Role of simple and complex hybrid revascularization procedures for symptomatic lower extremity occlusive disease. J. Vasc. Surg. 2010, 51, 1425-1435.e1. [CrossRef] [PubMed]

3. Kuma, S.; Tanaka, K.; Ohmine, T.; Morisaki, K.; Kodama, A.; Guntani, A.; Ishida, M.; Okazaki, J.; Mii, S. Clinical outcome of surgical endarterectomy for common femoral artery occlusive disease. Circ. J. 2016, 80, 964-969. [CrossRef] [PubMed]

4. Derksen, W.J.M.; Verhoeven, B.A.N.; Van De Mortel, R.H.W.; Moll, F.L.; De Vries, J.-P.P.M. Risk factors for surgical-site infection following common femoral artery endarterectomy. Vasc. Endovasc. Surg. 2008, 43, 69-75. [CrossRef] [PubMed]

5. Nguyen, B.-N.; Amdur, R.L.; Abugideiri, M.; Rahbar, R.; Neville, R.F.; Sidawy, A.N. Postoperative complications after common femoral endarterectomy. J. Vasc. Surg. 2015, 61, 1489-1494.e1. [CrossRef] [PubMed]

6. Zou, J.; Xia, Y.; Yang, H.; Ma, H.; Zhang, X. Hybrid endarterectomy and endovascular therapy in multilevel lower extremity arterial disease involving the femoral artery bifurcation. Int. Surg. 2012, 97, 56-64. [CrossRef] [PubMed]

7. Elbadawy, A.; Ali, H.; Saleh, M. Midterm outcomes of common femoral endarterectomy combined with inflow and outflow endovascular treatment for chronic limb threatening ischaemia. Eur. J. Vasc. Endovasc. Surg. 2020, 59, 947-955. [CrossRef] [PubMed]

8. Bone, R.C. Toward an epidemiology and natural history of SIRS (systemic inflammatory response syndrome). J. Am. Med. Assoc. 1992, 268, 3452-3455. [CrossRef]

9. Rutherford, R.B.; Baker, J.; Ernst, C.; Johnston, K.; Porter, J.M.; Ahn, S.; Jones, D.N. Recommended standards for reports dealing with lower extremity ischemia: Revised version. J. Vasc. Surg. 1997, 26, 517-538. [CrossRef]

10. Dormandy, J.A.; Rutherford, R.B. Management of peripheral arterial disease (PAD). TASC working group. TransAtlantic Inter-Society Consensus (TASC). J. Vasc. Surg. 2000, 31, S1-S296. [PubMed]

11. Szilagyi, D.E.; Smith, R.F.; Elliott, J.P.; Vrandecic, M.P. Infection in arterial reconstruction with synthetic grafts. Ann. Surg. 1972, 176, 321-323. [CrossRef] [PubMed]

12. Lameire, N.; van Biessen, W.; van Holder, R. Acute renal failure. Lancet 2005, 365, 417-430. [CrossRef]

13. Kechagias, A.; Ylönen, K.; Biancari, F. Long-term outcome after isolated endarterectomy of the femoral bifurcation. World J. Surg. 2007, 32, 51-54. [CrossRef] [PubMed] 
14. Nguyen, B.T.; Yu, P.; Tao, M.; Hao, S.; Jiang, T.; Ozaki, C.K. Perivascular innate immune events modulate early murine vein graft adaptations. J. Vasc. Surg. 2013, 57, 486-492.e2. [CrossRef] [PubMed]

15. Bonvini, R.F.; Rastan, A.; Sixt, S.; Beschorner, U.; Noory, E.; Schwarz, T.; Roffi, M.; Dorsaz, P.-A.; Schwarzwälder, U.; Bürgelin, K.; et al. Angioplasty and provisional stent treatment of common femoral artery lesions. J. Vasc. Interv. Radiol. 2013, 24, 175-183. [CrossRef] [PubMed]

16. Kang, J.L.; Patel, V.I.; Conrad, M.F.; LaMuraglia, G.M.; Chung, T.K.; Cambria, R.P. Common femoral artery occlusive disease: Contemporary results following surgical endarterectomy. J. Vasc. Surg. 2008, 48, 872-877.e1. [CrossRef] [PubMed] 